العدد العاشر

\title{
SYNONYMY IN ENGLISH
}

\author{
Asst . prof . abbas lutfi \\ Ph.D \\ University of Baghdad - collage of education - ibn rushd - English \\ department
}

\author{
M.A. Student Rahman Fahad Hussein \\ University of Baghdad College of Education-Ibn Rushd Republic of Iraq
}

\subsection{Introduction}

Crystal (2003:286) considers meaning as a basic notion that has been in linguistics as a central component of language. It has been studied by linguists widely over recent decades. Meaning has also been used as a criterion for the study of other concepts which are: semantics (meanings of words that have been shown by the same words), and pragmatics (meanings of words that have been held by the speakers). The notion of meaning is an intricate field in the human life, Therefore, it has been studied by many scholars of different fields (philosophers, psychologists, sociologists, literary critics, logicians, theologians and others). Linguists, on their part, are the scholars who advocate their studies to study meaning in the range of language. Those scholars attempt to explain how the meaning of vocabularies is structured and changed over time and this is covered by semantics.

Hudson (1984:4) directs his attention towards semantics .It is a science which studies the part of meaning that comes directly from the meanings of words in isolation and in relation with each other. One of those relations is the synonymous phenomenon.

Ducrol and Todorov (1981:236) try to define synonymy as any two expressions (words, groups of words, utterances) having the same meaning with different forms. The synonymous words or groups of words can be seen in the following examples:

$$
\begin{aligned}
& \text { (1-1) a- 'Pediatrician' / 'children's doctor' } \\
& \text { b- 'Go away' /'clear out' } \\
& \text { c- 'Start '/' begin' }
\end{aligned}
$$

The meaning of each pair is the same, but their forms are different.

Thornborrow and Wareing (1998:84) cite that synonymy has different signals. They might be achieved through the characteristics of the synonymous linguistic items. For instance, the verbs 'watch' and 'observe' sound synonyms, but they are not .The features of the verb 'watch' ought to be accompanied with moving things rather than with stationary ones; on the contrary, the verb 
'observe' is to be accompanied with stationary objects. Thus, they are not synonyms.

However, Lyons (1981:50) refers to the kinds of synonymy which can be classified into near synonymy, partial synonymy and absolute one. Lyons' perspective is not agreed upon by some other linguists like Finch (1999:49) who

rejects the existence of absolute synonymy. He states that absolute sameness, in meaning of lexical items, exists rarely. For example, the following pairs are not the same but they are similar:

(1-2)'die' / 'pass away' , 'broad' / 'wide', 'hide' /conceal',

Gleason (1965:467) expounds that the reason behind the use of synonymy is that it is used to avoid repetition of noun phrases, particularly when anaphoric pronoun is not possible or convention. 'The' should be used to indicate the synonymous use of the linguistic item, e.g.,

(1-3) a- 'I just saw a wonderful bargain at Smiths'

b- I just saw the wonderful bargain at Smiths'

Other linguists, such as Lado (1957:89), maintain that synonymy is used, for another reasons, as a way of facilitating learning a foreign language through listing sets of synonymous words.

\subsection{Synonymy as a Phenomenon}

Many linguists attempted to construct a detailed and comprehensive analysis and classification of synonymy, in English, in order to be understood and used easily and efficiently. However, it is not satisfactory at all to deal

with synonyms alone to get a total description of them. It is indeed very significant to discuss the origin, etymology of synonyms and so on to arrive at a clear picture of this phenomenon.

\subsection{Definition of Synonymy}

First of all, Marckwardt (1946: 168) views synonymy as a kind of changes in meaning, e. g.,

1) 'a tine vessel' may be called 'a pail ' in one section of England - (3 'a bucket ' in another place of England, also 'the child's and different terms . known by six or eight seesaw' is Through those changes, language seems either lavish or wasteful. Those changes refer to the synonymous fact (Baugh 1959: 216). Language sounds vague and uncertain out of synonymy (Dixon1966: 63). This nonspecific case of language might spring from the sameness of meaning for more than two linguistic forms. This occurrence will make language unstable semantically. 
For this reason, Bloomfield (1962: 45) insists that actual synonymy has never existed, since each linguistic form has its own specific meaning, e.g.,

(3 - 2) 'quick', ' fast ', ' swift ', ' rapid ', ' speedy'

Though those forms are synonyms, each has its own meaning which differs from the others. This linguistic diversity shows the difficulty that learners might face when they use different levels of synonymy as in the following linguistic considerations:

Words are similar in primary meaning but differ in connotations (close .' synonymy).

Words are similar in meaning but with restrictions in geographical.$_{r}$ distribution (near synonymy) (Lado 1957: 82).

However, Irmscher (1972: 370) announces the importance of synonymy being interchangeable items. This interchangeability of synonyms might be gained while the purport of the utterances has never been altered. This circumstance can not be obtained, such as:

(3 - 3) 'Start' and 'begin' are not synonyms in all their senses. 'Begin' the can not be substituted in: *'She started when I came into (Palmer 1972: 203). room suddenly'

Accordingly, it is possible to state that synonymy is a relation between two lexical units which have a shared meaning (Matthews, 1997:367). Lyons (1990: 60) assesses synonymy as expressions which have the same meaning. Through this definition two points can be noted:

Synonymy is not restricted to lexemes (semantic units) as they .' may allow simple and complex expressions.

The criterion of synonymy is the meaning of the linguistic.$r$ expressions.

Synonyms which have complex expressions are a kind of paraphrasing of words, phrases or sentences (written forms) or utterances (spoken forms) (Fromkin and Rodman 1993: 131). And this paraphrasing is a kind of translation (intralingual translation or rewarding) in which the verbal signs can be interpreted by means of other signs in the same language, i.e., the dictionaries of the same language are the examples of this kind of translation, e. g., 'Oxford Word Power $=$ English - English' and 'Oxford Advanced Learner's Dictionary' are dictionaries of this kind of translation (Jakobson 1987: 429).

Synonymy is a natural feature of language in which the sameness-of senses of different linguistic items formally- can be detected, e. g.,

(3 - 4) 'drunkness / drunken'

'poverty/ distressed' (Finch 1999: 148).

Thoronborrow and Wareing(1998: 84) mention the similarity of the linguistic items, e. g.,

(3-5) 'cash / money' 
'teenager / adolescent', etc.

The sameness of synonyms is again confirmed by Thakur (2001: 25), e.g.,

(3 - 6) 'freedom / liberty', ' hide / conceal'

'almost / nearly', ' snake / serpent' etc.

and he verifies synonymy as a paraphrased sentence, e.g., (ibid).

(3 - 7) 'John sold that car to Mary.'

'Mary bought this car from John.'

This view is rejected by Hayakawa ( $1994: 30$ ) who considers synonymy as just a criterion of words which share denotation, connotation and range of applicability, and this view has been indicated by Croft ( $2000: 176$ ).

Any synonymous pair depends upon two main intuitions which are:

1. Any two synonymous items bear a special sort of semantic resemblance, and

2. Some pairs of synonyms are more synonymous than other pairs, e.g.,

(3 - 8) 'Settee' and 'sofa ' are more synonymous than 'die' and ' kick the bucket'.

The degree of synonymy is a problematic subject, since it involves more precise and appropriate selected item which depends on its context. (Bell1993: 92).

Sometimes, this context makes language more flexible through limiting more than one synonym, for example, in the context of the following sentence: (3 - 9) 'What a nice -------- of flowers.'

The items ' range ', selection ' and 'choice' are synonyms (Crystal 2003: 450).

As a result, synonymy is a linguistic phenomenon in which two or more linguistic forms have been related semantically. And this relation is a relative one (Razmajoo 2004: 34).

This phenomenon has been based on some criteria which are: (1) synonymy can be accomplished with different linguistic items, and (2) This occurrence is a type of interpretation within the same language. This interpretation can be shown out of dictionaries and thesauri.

\subsection{Etymology of Synonymy}

Any word having the same meaning of another is called a synonym (' syn - 'name ' 'together'; and 'onyma ' means ' name' ), and 'onyma ' appears in English as 'onym ', e.g. ,

(4-1) Ladies novelists- once- published their works under pseudonyms names ', (pseude means 'false 'and 'anyma 'means false or'

(Funk1950: 398). 'name')

Old English poetry was rated as the source and the birth of synonymy in English. Synonymy was regarded as a kind of variation or description of 
language (Jesperson, 1954: 48). Jesperson (1957:222 - 225) considers Latin as another beginning of synonymy in English.

On his part, Bough (1959: 216) sees the Norman Conquest as the first stage of synonymy. The eighteenth century was reckoned to be the rise of synonymy. Through that period, synonymy was exemplified by some lists of phrases or words which had been initiated according to their resemblance, semantically (Dixon1966: 72). The source of the item 'synonymy ' is Greek. This item was ('syn' plus 'onama' which means ' with the same name') Burton (1987: 110).

It can be said that the expression ' synonymy ' has been accompanied with language since its outset. This utterance (synonymy) is a Greek one. Then it was realized by the Old English through the Norman Conquest in which many foreign words were used in addition to what had already existed. However, the eighteenth century was the frank date of applying the synonymous fact via the compilation process of English words.

\subsection{Signals of Synonymy}

The important signal of synonymy is the existence of the repetitive phenomenon of linguistic items which form the lexical cohesion in language. However, repetition sometimes cannot show the synonymous reality according to the criteria of synonymy. Those standards are exemplified in the sameness (of the synonymous items) semantically and the differences (of the synonymous items) formally, e.g.,

(5-1) a- 'I turned to the ascent of the peak.'

b- 'The ascent is perfectly easy.'

Though in those examples, one of those criteria (the differences formally) is ignored, the items ' the ascents ' are synonymous repetitively. But the repetition of the same lexical items is not always synonyms, such as:

(5-2) a-' John took Mary to the dance.'

b- 'John was left all alone.'

Paraphrasing ' John ' to be 'he' is the way in which the criteria (discussed above) of synonymy can be achieved (Halliday and Hasan1976:281-287). Despite the fact that Halliday and Hasan consider synonymy like the repetition (formally and semantically) of linguistic items in the structure of English, this situation cannot be achieved since synonymy might not be fulfilled unless its two criteria are available (the differences of the linguistic items formally and the semantic similarity at any context).

Nevertheless, Curse (1987: 88) thinks that signals of synonym are lexical relations which have a parallel identity as in:

(5-3) a- ' He plays the fiddle very well', and

b- ' He plays the violin very well.' 
Through those two sentences the synonymous items 'fiddle ' and 'violin ' can be employed without changing the sense.

Nonetheless, synonymy is the situation whereby lexical items whose sense is identical in respect of ' central ' semantic traits, but they differ only in respect of what one may provisionally describe as 'minor 'or' peripheral' traits. Therefore, synonymy is a way that is used to clarify the meaning of any linguistic item by using other words through adopting some linguistic signals which are:

1. Using some expressions such as ' that is to say ' or a particular variety of 'or', e. g.,

(5-4) a. 'He was cashiered, that is to say, dismissed'

b. 'This is an ounce, or snow leopard', and

2. Synonyms are used contrastively in some signals, as in:

'more exactly ' or ' or rather', e. g.,

(5-5) a. 'He was_murdered_or rather executed.'

b. 'On the table there were a few grains, or more exactly, the substance.' (ibid). of granules

In addition to the lexical signals above, there are some semantic signals which are:

1. Synonyms have arousal meanings which reflect feelings as well as ideas.

(5-6) a- ' slay ' and 'kill' ' can be substituted, but

b- 'slain ' and ' kill' can not be substituted in the following headline : newspaper

(5-7) 'Fifteen killed on County's Roads in Bank Holiday Black Week.'

2 . Though some synonyms seem very similar in their meanings, they are slightly different, such as: 'begin' and 'start'. 'Started' rather than 'began' ought to be chosen to fill the gap of this sentence:

(5-8) 'The mayor ----- the 3.3 race at Stanwood, run over two half miles for the newly presented Borough Trophy.'

$a$

3. The context of a sentence, a paragraph and a passage ought to limit the appropriate synonyms, e.g., 'buy / purchase' and 'live /reside'. Those can not be randomly employed. They might be used according to the context of a sentence, paragraph and a passage.

4. The sounds of words are a very important standard to indicate the appropriate synonymy, e. g., 'Through this jungle' 'The general generally expects his subordinates to report their major decisions to him in writing '. Here, through this sentence, 'generally ' can be substituted by 'usually' and 'general' by 'Chief' to suit the context of sounds. Thus, euphony is a signal which ought to be considered in choosing synonymous words (ibid: 110). 
Occasionally, the characteristics of synonymous items are deemed the best signals of synonymy, e. g.,

(5-9) The verbs: ' watch ' and 'observe ', are synonyms but each one of them has its own features. 'Watch' should be accompanied with the moving things rather than stationary things, but 'observe' is for stationary things (Thornborrow and Wareing1998: 84).

Mainly, the signals of synonymy can be indicated by some hints as in the following: of certain synonymous linguistic items which are -The repetitive hints .1 are signals of -employed to be cohesive devices within language synonymy.

of some certain linguistic forms with their own - The descriptive points.$r$ will mirror synonymous notions, as in examples (5-4) and -equivalents (5-5).

The equivalent arousal meaning might make some pairs of synonyms, as in the examples; (5-6) and (5-7).

The similarity of senses (the mutual alternative relation between meanings . of certain words to be synonymous) is a clue of synonymy.

The appropriate context will indicate the signals of synonymy as in .0 example (5-8).

will indicate the - of linguistic items -At least, the nuances of meaning . . synonymous fact as in (5-9).

are the best signals of synonymy, i.e., -of formality -The conventions .V signals of synonymy can be demonstrated through the conventions of speech community.

\subsection{Kinds of Synonymy}

Though synonymy is a fact within an individual language, Lado (1957:82) is not - of meaning for different forms - believes that the complete sameness expressed in the same language. The similarity of meaning can be shown with translation from language to another by forming a synonymous item in the foreign language to correspond to the meaning of a different form of the natives. Therefore, those items will be synonyms. For example., the word 'book' in means 'a number of sheets of paper, fastened - as a native language - English together inside a cover, with word printed on them for people to read'. If this word ('book') is translated into Arabic, it will be introduced in another different form which is 'Kitaab'. It shows the same meaning of English. Thus, the exact synonymy can be achieved.

But this view can not be accepted since synonymy can not be fulfilled through two languages. This notion ought to be only gained through an individual language, such as Arabic or English etc. individually. The exact 
synonymy does not exist in English. The semantic divergences of synonymy might be easily realized; e. g., the words 'hearty ' and ' cordial ' seem synonyms since they refer to the sense of heart. There is a slight difference between; 'Hearty' which can be employed into 'hearty dinner' not with ' hearty reception' and vice- versa for 'cordial'. In English, there is only one kind of synonymy which is called the close one (Baugh 1959: 217 - 218).

Halliday and Hasan (1976: 287) classify synonymy into two kinds which are: exact synonymy, for example, 'climb 'is the synonym of ' ascend '; and near - synonymy, for example, ' bromd ' means ' sword'.

The idea of the exact synonymy is also proved by Fromkin and Rodman (1978: 180) who show this kind through paraphrasing sentences, e. g.,

(6-1) a- 'It is easy to please John.'

b- 'John is easy to be pleased.'

However, near synonymy is a pair of words that have never been fully substitutable, for example, the word ' foe 'emphasizes ' active warfare more than 'enemy' does (Gove1984: 93). And the pairs of near-synonymy, sometimes, share through the core - meaning but differ stylistically (Inkpen and Hirst 2001: 13). The stylistic synonymy is also supported by Finch (1999: 149). Nearsynonymy might be adopted within the explanations of some dictionaries (Curse 1987: 240).

Hasan ( 2009 : 5 ), on his side, depends on what has been introduced by Hirst (1995) and Edmonds (1999) who consider near-synonymy as a correction of absolute , true and complete synonymy .

Absolute synonymy is a kind of synonymy in which a pair of words might be substituted at any context, e. g.,

(6-2) 'pavement' is a complete synonym of 'sidewalk' (Todd, 1989:81).

He also indicates other kinds of synonymy which are:

1. Stylistic synonymy, e. g.,

(6 - 3) 'die', 'over '/' pass on ', ' kick the bucket'

2. Cognitive synonymy (arousal or emotional one), e. g., (6-4)

'A'
'conceal'
'politician'
'stubborn'

'B'

'hide'

'statesman' 'resolute'

(ibid)

The latter kind is confirmed by James (1981: 96), e. g.,

(6-5) 'Freedom / liberty', ' hide / conceal'

Tackling absolute synonymy once again, Bell (1993:93) rejects this kind entirely but he maintains the partial one (close synonymy), e. g.,

(6-6) 'Hide / conceal '. 
Though the absolute synonymy exists, its rarity is indicated by Elgin (1979:19) who indicates one kind of synonymy which is the perfect one. Lyons ( 1979 : 447 )refers to it through quoting Ullmann who states: 'It is almost a truism that total synonymy is an extremely rare occurrence, a luxury that formed afford'. Cruse (1987: 89) limits real synonymy which -language can ill can be positioned between the absolute synonymy (which is rejected) and the zero one. Matthews (1997:367), on his part, names it as the partial synonymy. Finch (1999:149) and Kearns (2000:10) name it as a true one. Thornborrow and Wareing (1998: 84), on their part, support the incomplete synonymy.

Lyons ( $1981: 50$ ) refuses absolute synonymy but again he mentions it through categorizing kinds of synonymy which are: near-synonymy in which semantically ; - but not identical - the expressions are more or less similar partial synonymy and absolute synonymy which covers the range between the two ( near and partial synonymy ) kinds above (ibid 1996: 61).

Generally, kinds of synonymy can be categorized in:

\section{Table (2-1) kinds of synonymy and their criteria}

\begin{tabular}{|c|c|}
\hline Kinds of synonymy & Their criteria \\
\hline $\begin{array}{l}\text { Absolute / exact / perfect / . } \\
\text { total / theoretical synonymy }\end{array}$ & $\begin{array}{l}\text { The sameness between synonyms } \\
\text { ought to exist(Lado1957:82) } \\
\text { This kind of synonymy can be } \\
\text { observed in paraphrasing of } \\
\text { sentences as in : } \\
\text { a. It is easy to seeJohn. } \\
\text { b. John is easy to beseen. } \\
\text { (Fromkin and Rodman 1978:180). } \\
\text { can - of this kind-The synonyms } \\
\text { be interchanged at any context } \\
\text { (Todd1989:81). } \\
\text { This kind is a type of luxury of . } \\
\text { language (Lyons1979:447). } \\
\text { It is a rare kind but it is a possible . } \\
\text { one (Finch1999:149). } \\
\text { Exact synonymy can be . } 7 \\
\text { accomplished through a short time } \\
\text { and particular situations. } \\
\text { It is an argumentative point between } \\
\text { the experts since each word has its } \\
\text { own meaning. }\end{array}$ \\
\hline Partial synonymy.$r$ & It has relative sameness . \\
\hline
\end{tabular}




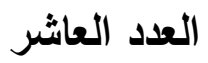

\begin{tabular}{|l|l|}
\hline & (Baugh1959:217-218). \\
It has filled the area between other \\
kinds of synonymy which are the \\
exact and the near synonymy \\
(Cruse1987:89). \\
Its interchangeability is a relative \\
standard.
\end{tabular}

\subsection{Reasons for Synonymy}

At first, though synonymy had not been named frankly, some specialists mentioned its reasons. Synonymy might exist for an arousal situation which has been expressed by more than one speaker (King and Ketly1941:22). Sometimes, synonymy can be represented as a type of change of meanings

(Markwardt1946:171). On another time, synonymy is possible through a special environment of speech community (Jesperson 1954: 49).

After illustrating synonymy, its reasons can be indicated easily. On the one hand, synonymy has been used as an approach of facilitating learning foreign language through listing its synonymous items to control the area of meanings (Lado1957: 87). On the other hand, synonymy can be adopted to be used as material of explanation in some dictionaries, for example, the word ' man' is a synonym of ' human being' (Branddok1962: 266). Gleason (1965:467) indicates two reasons for synonymy:

1. Synonymy is used to eliminate the ambiguity, e.g.,

(7-1) 'The killing of the lion was wanton act.'

Here, the ambiguity can be shown easily but to eliminate that, the sentence ought to be: 
(7-2) 'The shooting of the lion was a wanton act.'

2. Synonymy is used to avoid the repetition of noun phrase, particularly, in which the anaphora of pronoun is not possible or convenient. 'The' should be used to limit the synonymous use of the previous linguistic item. The noun may be completely new in the discourse but using 'the' is a signal of the synonymous old one, e. g.,

(7-3) a- 'I just saw a wonderful bargain at Smith's.'

And its synonymous one is:

b- 'I just saw the most wonderful bargain at Smith's.'

Gleason (1995:329) also adds another reason for synonymy. This reason is the stylistic one in which a special effect is desired to be adopted within English. Some scholars justify synonymy in different reasons. Synonymy is considered as a kind of maneuver in which some synonymous items can be employed descriptively, expressively or socially (Lyons1990: 148). But, the entailment is considered the main reason of synonymy syntactically, e. g.,

(7-4) a- 'Evelyn won the race'. 'The race was won by Evelyn.'

b- 'I bought some ripe tomatoes'.'I purchased some ripe tomatoes.'

c- 'My dog is bigger than your dog'. 'Your dog is smaller than my dog.'

And connotative meaning is another reason for synonymy, for example, the word 'piss' has negative connotations which ought to be replaced by its synonyms 'going to the toilet' (Kuiper and Allan 1996: 165).

Husdson (2000:255) refers to some reasons for synonymy. One of those reasons is the conventional one, for example, 'twelve' and 'dozen', 'sick' and 'ill'. Sometimes, synonymy is used to facilitate the translation by choosing near synonyms through translating process (Edmonds1999:215). Chiefly, synonymous phenomenon might be imposed historically, environmentally, socially or technically.

\subsection{Limitations of Synonymy}

Synonymous items should be confined by the sameness of their meanings and the difference of their forms (Lado1957: 91). Alston (1964: 44) states that synonyms are subject to certain conditions in which they ought to be substituted mutually without altering their meaning. Gleason (1965: 429) refers to the significance of the associative or connotative meaning of the synonyms.

Palmer (1972: 203) puts two curbs against the synonymous fact. Those restrains are: the interchangeability of synonyms and their emotive meanings. This emotive meaning will perplex the foreigner through distinguishing the fit choice of the synonyms, e. g.,

(8-1) a- ' The poor little boy', and

b- 'The poor small boy.' (Brook1977:168). 
The conventionality (normality) is a restricted condition of synonymy, e.g.,

(8-2) 'vixen' and ' duck ' have their synonyms 'female fox ' and '

, 'male duck

but this case can not be applied to:

(8-3) 'cow' and 'bull',

which do not conventionally have synonyms 'female cow' and 'male cow' (Lyons1979: 451).

However, Allan (1986:176) has just indicated synonymy as a sense relation not the sameness of reference; for example, 'the morning star' is different from 'the evening star' though the reference is the same (the reference is a planet which is called Venus).

limits the individual attitudes - on her part - B But then, Hasan (2009:3) towards choosing the synonyms. Sometimes the choice of synonyms can be established according to their simplicity, for instance, near synonyms can help disambiguate each other and the context in which they occur is the typical way (Inkpen 2003:13), e.g., of differentiating their sense

(8-4) 'The boy told fibs. '

The word ' $f i b$ ' is one of group of words, all of which mean 'lie', this group include 'lie', 'falsehood', 'prevarication' , 'fib' and 'untruth'. Among this cluster of near- synonyms, ' $f i b$ ' is chosen because it satisfies the preference better than others (Lin et. al. 2003:181:3).

Synonyms, according to Curse ( $1987: 265$ ), can not be categorized systematically; therefore, the synonyms ought to be : (1) having resemblances and permissible differences, and (2) chosen according to their context. And the than - by the language user-synonym of a native source is more preferable one its borrowed synonym; since the synonyms of the natives are more economic than the borrowed ones, e. g.,

(8-5) native synonyms

$$
\begin{aligned}
& \text { Dog } \\
& \text { Boy }
\end{aligned}
$$

borrowed synonyms

$$
\begin{aligned}
& \text { hound } \\
& \text { knave }
\end{aligned}
$$

(Robertson 1954: 181)

Primarily, the synonymous notion might be accomplished between pairs of synonyms through some limitations which are:

1- Synonyms ought to be having the sameness semantically.

2- The forms of the synonyms ought to be different.

3- Synonymous items ought to be interchanged mutually.

4- Pair of synonyms ought to be accepted cognitively, conventionally and contextually.

5- The semantic components of the synonyms ought to be intersected.

\section{CONCLUSIONS}


Through this research, the researcher gains the following findings:

Synonymy is a universal linguistic phenomenon which exists .' within the linguistic system of every language.

This notion is very important as it sheds light on the ways in which.$^{r}$ linguistic items (lexical items) gain their meanings through other linguistic items under certain conditions and according to certain linguistic behavior.

Synonymy is a linguistic fact that has been found for a long time .r ago in English.

English has the many synonymous reasons which are historical, .. social and technical one.

Some specialists of English consider the complete synonymy as a.$^{\circ}$ luxurious linguistic aspect. On the other hand, some of them regard it as an unnecessary linguistic swelling.

Therefore, the synonymous phenomenon is worth studying since no .7 conclusive solution is sought to the controversial claims raised by several linguists. Where there is no clear consensus among them on the description of this notion, this research is an attempt which cuts through the welter of the variety of treatments and provides a unified account of this concept in English.

\section{BIBLIOGRAPHY}

Paul Ltd. $\quad$ Allan, Keith. (1986). Linguistic Meaning. London: Routledge and Kegan Hall, Inc. Alston, William, P. (1964). Philosophy of Language. Illinions: Prentice -

Routledge Baugh Albert, C. (1959). A History of the English Language. London: and kegan Paul Ltd.

London: Bell, Roger, T. (1993). Translation and Translating Theory and Practice. Longman.

Branddock, Richard. (1962). Introductory Readings of the English

Language. Iowo: Prentice - Hall, Inc. Englewood Cliffs, N.J.

Brook, G. L. (1977). History of the English Language. London: Andre Deutch.

Burton, S. H. (1987). Mastering English Language. London: Macmillan.

Croft, William. (2000). Explaining Language Change. London:Longman.

Cruse, D.A. (1987). Lexical Semantics. Cambridge: Cambridge

Press. University 
Linguistic

Dixon, Robert M.W. (1966). What is Language: A New Approach to

Discription. London: Longman.

of the Ducrol, Oswald and Tzvetan Todorov. (1981). Encyclopedia Dictionary

University Press.

Sciences of the Language. Oxford: John Hopkins

Edmonds, P. (1999). Semantic Representation of Near-Synonyms For

Toronto: Toronto $\quad$ Automatic Lexical Choice. Ph .D.thesis University of Toronto.

University press.

Englewood

Cliffs.

Press. $\quad$ Finch, Geoffrey. (1999). How to Study Linguistics. New York:St.Martin's

Holt, $\quad$ Fromkin and Rodman. (1978). An Introduction to Language . London:

Rinthart and Winston.

Words $\quad$ Funk, Wilfred. (1950). Word Origins: An Exploration and History of and Language. New York: Wings Books.

Holt, Gleason, Jr, H. A. (1965). Linguistics and English Grammer. New York:

Rinehart and Winston, Inc.

Stand Gove, P. (1984). Webster's New Dictionary of Synonyms. Stand Ford:

Ford University press .

Crystal, D. (2003). A Dictionary of Linguistics and Phonetics. London:

Publishing Ltd. Blackwell

Halliday and Hasan. (1976). Cohesion in English. London: Longman.

Hasan, W. H. (2009). The Concept and the Use of Synonyms. Damascus:

Damascus University Press.

Hayakawa. (1994). Choose the Right Word. London: Harper Collins

Publisher.

Inc. Hudson, R. (1984). Invitation to Linguistics. New York: Basil Blackwell

Synonyms Inkpen and Hirist, G. (2001). Building a Lexical Knowledge Base of Near

Differences . London: Harper Collins Publishers.

Rinehart Irmscher, William, F. (1972). The Holt Guide to English. New York: Holt and Winston .Inc.

Jakobson, R. (1987). Language in Literature. London: Longman.

Press. James, Carl. (1981). Contrastive Analysis. Oxford: Oxford University

Oxford: $\quad$ Jespersen otto. (1954).Growth and Structure of the English Language.

Oxford University Press.

Kearns, Kate. (2000). Semantics. New York: St. Martin's Press LLC,

Scholarly and Reference Division.

Critical King, Alec. and Ketley, Martin. (1941). The Control of Language : A

Approach to Reading and Writing. London: Longman.

Language Kuiper, Koenraad and W. Scott Allan. (1996). An Introduction to English :Soun, Word and Sentence. London: Aaron typLtd.

University Lado, Robert. (1957). Linguistics Across Cultures. Michigan: The of Michigan Press.

and Lin et. al. (2003). Introducing English Semantics. London : Routledge

Paul Ltd. Kegan

Lyons, J. (1981). Language, Meaning and Context . London: Richard

Clay, the Chaucer press.

University Press. . (1979). Semantics V. Cambridge: Cambridge 
University Press.

Cambridge

University Press.

(1996). Linguistic Semantics: An Introduction. Cambridge:

Oxford:

Marckwardt, Albert, H. (1946). Introduction to the English Language.

Oxford University Press.

Oxford: $\quad$ Matthews, P.H. (1977). The Concise Oxford Dictionary of Linguistics.

Oxford University Press.

Palmer, F.R.(1972). Descriptive and Comparative Linguistics. London: Faber and

Faber 3 Queen Square.

Linguistic.

Razmjoo, Seyyed Ayatollah.(2004). Fundamental Concepts in

Tehran: Rahnama Press.

Wisconsin:

Robertson, Stuart. (1954). The Development of Modern English.

Prentice-Haii, INC. Englewood Cliffs, N.J.

Thakur, Damodar. (2001). Linguistics Simplified Semantics. Delhi:

Bharati

Bhawan.

Thornborrow, Joanna. and shanWareing. (1998). Patterns in Language.

Paul Ltd. and Kegan London: Routledge

Todd, Loreto. (1989). An Introduction to Linguistics. London: Longman. 